\title{
New insights into benefits of combination treatment with yttrium-90 and gemcitabine in patients with intrahepatic cholangiocarcinoma
}

\author{
Alexander I. Damanakis, Florian Gebauer, Christiane Bruns \\ Department of General, Visceral, Cancer and Transplantation Surgery, University Hospital of Cologne, Cologne, Germany \\ Correspondence to: Alexander I. Damanakis, MD. Department of General, Visceral, Cancer and Transplantation Surgery, University Hospital of \\ Cologne, Kerpener Strasse 62, 50937 Cologne, Germany. Email: alexander.damanakis@uk-koeln.de. \\ Comment on: Nezami N, Camacho JC, Kokabi N, et al. Phase Ib trial of gemcitabine with yttrium-90 in patients with hepatic metastasis of \\ pancreatobiliary origin. J Gastrointest Oncol 2019;10:944-56.
}

Submitted Nov 30, 2019. Accepted for publication Dec 31, 2019.

doi: 10.21037/jgo.2020.01.01

View this article at: http://dx.doi.org/10.21037/jgo.2020.01.01

The treatment of patients with irresectable hepatic metastases of pancreatic cancer (PC) and intrahepatic cholangiocarcinoma (ICC) remains challenging despite growing therapeutic options and providing adequate palliative care always includes the decision between quality of life and most effective oncologic results. Gemcitabine is a relatively well tolerated substance but median overall survival of patients with PC or ICC with metastases treated with gemcitabine monotherapy was reported 5.7 (1) and 8.1 (2), respectively.

Selective internal radiation therapy (SIRT) or transarterial radioembolization (TARE) has emerged as a treatment option for patients with primary or secondary hepatic malignancies that are usually not eligible for surgical treatment $(3,4)$. Microspheres loaded with yttrium-90 $\left({ }^{90} \mathrm{Y}\right)$ are applied in the hepatic artery after radiologically guided selective catheterization allowing for a more precise radiation of tumor tissue while only mildly affecting liver tissue.

Still, SIRT with or without synchronous chemotherapy is not widely evaluated in hepatic metastases of PC and ICC and most studies only have small number of cases rarely exceeding 20 treated patients. Intraarterial therapy (including two patients treated with TARE) for multifocal ICC was compared to surgical resection in a collective of 116 patients with no statistically significant difference in overall survival, support the effect of local therapies in the liver (5). A single center study for PC patients with hepatic metastases reported partial response or stable disease in 9 of
13 patients and median overall survival of 12 months after TARE (6) and another publication in a similar collective with 16 patients could show an objective response in $47 \%$ and a median survival of 9 (range, 0.9-53.0) months after previous gemcitabine-based chemotherapy (3). Thirtythree patients with metastatic PC that had progressed under systemic chemotherapy and other oncologic treatments underwent TARE at one of three institutions with partial response or stabile disease in $79 \%$ (7).

In an article now published in the fournal of Gastrointestinal Oncology by Nezami and colleagues 8 patients (three with PC and 5 with ICC) that had not received prior systemic therapy for advanced stage disease underwent TARE with ${ }^{90} \mathrm{Y}$ and concomitant gemcitabine within an open-label phase Ib clinical trial. Patients with unilobar disease $(n=4)$ received one treatment with TARE at day 2 after first gemcitabine therapy and patients with bilobar disease $(n=4)$ received a second treatment at day 37. All patients had a tumor burden of $>50 \%$ of total liver. Majority of patients were female, and the mean age was $69.4 \pm 6.9$. Due to an early death of one patient 1.2 months after ${ }^{90} \mathrm{Y}$ TARE, seven patients were eligible for tumor response evaluation. Response was evaluated using positron emission tomography/computed tomography (PET/CT) scan. Overall, there was a treatment response rate of $62.5 \%$ at 3 months. There was a statistically significant better objective response in ICC patients. The median hepatic progression free survival (HPFS) for PC was 4.4 (1.2-4.9) as compared to $16.3(2.7-22.5)$ months in ICC patients 
$(\mathrm{P}<0.001)$. Median progression free survival of all patients was 6.9 (1.2-22.4) months. The authors report, that there was no non-targeted embolization according to a post${ }^{90} \mathrm{Y}$ treatment single-photon emission CT (SPECT)/CT scan (bremsstrahlung). There was one case of full response in a patient with ICC. All patients encountered transient fatigue representing the most common treatment-associated complication. Transient liver toxicity after ${ }^{90}$ Y-TARE and gemcitabine occurred in $7(87.5 \%)$ patients. None of the toxicities were permanent and also no persistent hepatobiliary toxicity was reported within 90 days.

The results provided by Nezami and colleagues are of great interest and clinically relevant because they show the feasibility of applying systemic chemotherapy and TARE in patients with hepatic metastasis of pancreatobiliary origin and prove that even full response is possible. They showed that a dosage of up to $600 \mathrm{mg} / \mathrm{m}^{2}$ gemcitabine could safely be applied in seven of the eight patients with higher grade (grade 2-3) hepatobiliary toxicity being only transient in three patients. PET/CT scan showed a response rate of $62 \%$ which is in accordance with other publications in the field $(3,7)$. However, only a small sample size could be included, and enrolment had to be stopped because there were not enough chemotherapy naïve patients. This addresses a common issue of patient selection for local ablative procedures. Even though the authors did not report any significant post ${ }^{90} \mathrm{Y}$-TARE complications, treatment with radioembolization can lead to post-radioembolization syndrome causing, among others, gastrointestinal ulceration and radiation pneumonitis. Therefore, patient selection and preparation by strict inclusion criteria, as was done here, enrolling only patients with adequate liver function and determination of lung shunting fraction $<20 \%$ before therapy plays a crucial role when planning TARE. All this is a limitation for TARE application because in the clinical reality, many patients with systemic disease and predominant hepatic manifestation have already impaired liver function due to past chemotherapy or the malignancy itself. Also, gemcitabine is not the only available treatment for patients with metastatic PC and ECOG $0-1$ as newer studies report $(8,9)$, a fact that should be considered in the interpretation of the data. On the other hand, as toxicity from systemic chemotherapy should be limited when applying ${ }^{90}$ Y-TARE, and gemcitabine properties of radiosensitization were aimed for in this study, monotherapy with gemcitabine is reasonable even in the context of newly available data. For the 5 ICC patients, ${ }^{90}$ Y-TARE response was significantly better compared to the PC patients, as was the HPFS with $4.4(1.2-4.9)$ for PC $v s$. $16.3(2.7-22.5)$ months for ICC $(\mathrm{P}<0.001)$. ICC patients in the palliative setting are treated usually with gemcitabinebased systemic chemotherapy showing only moderate effects on response and survival (10). Especially in the light of more systemic treatment options for PC patients, the benefit of ${ }^{90}$ Y-TARE might be greater in ICC patients and thus data by Nezami and colleagues provided here is a considerable base to further conduct randomized trials with a focus on ICC patients.

\section{Acknowledgments}

Funding: None.

\section{Footnote}

Provenance and peer review: This is an invited article commissioned by the editorial office, Fournal of Gastrointestinal Oncology. This article did not undergo external peer review.

Conflicts of Interest: All authors have completed the ICMJE uniform disclosure form (available at http://dx.doi. org/10.21037/jgo.2020.01.01). The authors have no conflicts of interest to declare.

Ethical Statement: The authors are accountable for all aspects of the work in ensuring that questions related to the accuracy or integrity of any part of the work are appropriately investigated and resolved.

Open Access Statement: This is an Open Access article distributed in accordance with the Creative Commons Attribution-NonCommercial-NoDerivs 4.0 International License (CC BY-NC-ND 4.0), which permits the noncommercial replication and distribution of the article with the strict proviso that no changes or edits are made and the original work is properly cited (including links to both the formal publication through the relevant DOI and the license). See: https://creativecommons.org/licenses/by-ncnd/4.0/.

\section{References}

1. Burris HA 3rd, Moore MJ, Andersen J, et al. Improvements in survival and clinical benefit with gemcitabine as firstline therapy for patients with advanced pancreas cancer: a 
randomized trial. J Clin Oncol 1997;15:2403-13.

2. Valle JW, Wasan H, Johnson P, et al. Gemcitabine alone or in combination with cisplatin in patients with advanced or metastatic cholangiocarcinomas or other biliary tract tumours: a multicentre randomised phase II study - The UK ABC-01 Study. Br J Cancer 2009;101:621-7.

3. Michl M, Haug AR, Jakobs TF, et al. Radioembolization with Yttrium-90 microspheres (SIRT) in pancreatic cancer patients with liver metastases: efficacy, safety and prognostic factors. Oncology 2014;86:24-32.

4. Kennedy A, Nag S, Salem R, et al. Recommendations for radioembolization of hepatic malignancies using yttrium-90 microsphere brachytherapy: a consensus panel report from the radioembolization brachytherapy oncology consortium. Int J Radiat Oncol Biol Phys 2007;68:13-23.

5. Wright GP, Perkins S, Jones H, et al. Surgical resection does not improve survival in multifocal intrahepatic cholangiocarcinoma: a comparison of surgical resection with intra-arterial therapies. Ann Surg Oncol

Cite this article as: Damanakis AI, Gebauer F, Bruns C. New insights into benefits of combination treatment with yttrium-90 and gemcitabine in patients with intrahepatic cholangiocarcinoma. J Gastrointest Oncol 2020;11(5):833-835. doi: 10.21037/jgo.2020.01.01
2018;25:83-90.

6. Kim AY, Unger K, Wang H, et al. Incorporating Yttrium-90 trans-arterial radioembolization (TARE) in the treatment of metastatic pancreatic adenocarcioma: a single center experience. BMC Cancer 2016;16:492.

7. Kim AY, Frantz S, Brower J, et al. Radioembolization with Yttrium-90 microspheres for the treatment of liver metastases of pancreatic adenocarcinoma: a multicenter analysis. J Vasc Interv Radiol 2019;30:298-304.e2.

8. Von Hoff DD, Ervin T, Arena FP, et al. Increased survival in pancreatic cancer with nab-paclitaxel plus gemcitabine. N Engl J Med 2013;369:1691-703.

9. Conroy T, Desseigne F, Ychou M, et al. FOLFIRINOX versus gemcitabine for metastatic pancreatic cancer. $\mathrm{N}$ Engl J Med 2011;364:1817-25.

10. Chun YS, Javle M. Systemic and adjuvant therapies for intrahepatic cholangiocarcinoma. Cancer Control 2017;24:1073274817729241. 